\title{
Perception of internet addiction among psychiatric residents in an urban area in Indonesia
}

Enjeline Hanafi, Kristiana Siste, Andreas Kurniawan, Martina Wiwie Setiawan Nasrun, Irmia Kusumadewi

pISSN: 0853-1773 • elSSN: 2252-8083 https://doi.org/10.13181/mji.v28i4.3316 Med J Indones. 2019;28:380-5

Received: November 24, 2018

Accepted: August 10, 2019

Authors' affiliations: Department of Psychiatry, Faculty of Medicine, Universitas Indonesia, Cipto Mangunkusumo Hospital, Jakarta, Indonesia

\section{Corresponding author:}

Irmia Kusumadewi Department of Psychiatry, Faculty of Medicine, Universitas Indonesia, Jalan Pangeran Diponegoro No. 71, Kenari, Senen, Central Jakarta 10430, DKI

Jakarta, Indonesia

Tel/Fax: +62-21-3107741/

$+62-21-3106218$

E-mail: irmiakusumadewi@yahoo.com

\begin{abstract}
BACKGROUND In the last two years, many suspected cases of internet addiction have been reported by the media. However, many physicians do not have comprehensive knowledge of internet addiction. Currently, there has been no study conducted among psychiatric residents. This study was aimed to determine the perception of internet addiction among psychiatric residents.
\end{abstract}

METHODS This cross-sectional study was done from April to May 2018. Subjects were recruited by a total sampling method consisting of all psychiatric residents of the Faculty of Medicine, Universitas Indonesia. Perceptions of internet addiction were measured using the illness perception questionnaire revised version for addiction. The calculation of subscales was based on the algorithms available for this instrument. The Mann-Whitney $U$ test was used to determine the association of different years of psychiatric education and the perception of internet addiction.

RESULTS Fifty-two subjects completed the survey, and $85 \%$ of them reported feeling that they did not have adequate knowledge of internet addiction. They believed that their current knowledge was not sufficient to make diagnosis and management decisions. Junior residents had significantly lower consequence scale scores, with mean (standard deviation) scores of 4.1 ( 0.54$)$ for juniors and $4.4(0.48)$ for seniors $(p=0.021)$.

CONCLUSIONS Psychiatric residents perceived internet addiction as emotionally stressful, understandable, and cyclical, but difficult to control. Senior psychiatric residents had a better perception internet addiction consequences compared with their juniors, who have received only basic knowledge about addiction without clinical exposure, but the perceptions could still be improved.

KEYWORDS addictive, education, internet, physicians, psychiatry
Internet addiction was first described by a psychiatrist more than 10 years ago as the condition of a maladaptive pattern of internet use leading to clinical impairment or distress. ${ }^{1,2}$ Researchers use different terms to describe this condition, such as pathological internet use, internet addiction, internet dependency, problematic internet use, and technological addiction. The Diagnostic and Statistical Manual of Mental Disorders, fifth edition (DSM-V) is the beginning stage at which behavioral addiction begins to be taken seriously, with a new classification of pathological gambling. ${ }^{3}$ The DSM-V also includes internet gaming as a disorder that requires further research. The International 
Classification of Disease 11th (ICD-11) revision draft follows in the footsteps of DSM-V and proposes new diagnostic criteria, namely for gaming disorders, which are characterized as persistent and recurrent online and offline gaming behavior patterns that lead to significant impairment in personal, family, social, educational, occupational, or other important areas of functioning and would normally have been evident for at least 12 months. ${ }^{4}$

The failure to identify any kind of addiction problems may lead to complications and poorer response to therapies..$^{5-10}$ Identifying addiction is still challenging due to inadequate knowledge on addiction, prejudices held by professionals regarding addiction, and certain work characteristics. ${ }^{9}$

In teaching hospitals, residents are the physicians who provide direct care for the majority of inpatients and outpatients. ${ }^{6}$ Residents' confidence is an important factor in assessing and managing patients' conditions. Although confidence and preparedness are different, these two aspects remain closely related. Greater confidence in assessment and intervention for behavioral addiction, in this case internet addiction, has been associated with increasing preparedness. Many studies have addressed physicians' and medical students' knowledge and attitudes toward addictions. ${ }^{6,7,9,11-16}$ Improvement in different aspects of medical education by integrating addiction training into the general medical curriculum has been proposed. ${ }^{9}$

Internet addiction as a newer type of addiction is not as well-known as other kinds of addictions. However, caution should be taken since many suspected cases of internet addiction have been reported by the media in the last two years. ${ }^{17}$ Psychiatric residents are among the physicians who could have made this diagnosis. This is of particular relevance in the context of students in training to be psychiatrists, since these students will be future therapists for patients with addiction problems. Therapists should be as neutral as possible. It is easier to change the perception of students. Currently, no study has been conducted among psychiatric residents, so no information could be obtained from this particular important cohort, who are partly responsible for treating people with psychiatric problems such as internet addiction. This study was aimed to determine the perception of internet addiction among psychiatric residents.

\section{METHODS}

\section{Subjects}

This cross-sectional study was conducted from April to May 2018. Subjects were recruited by using a total sampling method. There were 52 active psychiatric residents in Faculty of Medicine, Universitas Indonesia during sampling period. The choice of the location was considered appropriate to represent the perception of mental health professionals in urban areas, as internet addiction is still considered more common in urban areas. All subjects were approached individually and given an explanation about the objectives of the study and its confidentiality. After informed consent was obtained, the subjects were asked to fill in online forms with personal data (age, gender, and characteristics of internet use) and fill out a perception questionnaire. None of the residents refused to participate in this study. The baseline characteristics from personal data were obtained to show that the residents could underdiagnose the condition based on their characteristics of daily use of the internet. In filling the characteristic of internet use questions, the subjects could only choose one best answer to describe their conditions. The presence of internet addiction among residents was not measured due to ethical problems as this study used total sampling of psychiatric residents of the Faculty of Medicine, Universitas Indonesia. All procedures performed in this study were following the ethical standards of the research committee of the Faculty of Medicine, Universitas Indonesia (No: 150/UN2.F1/ ETIK/2017).

In this study, subjects were grouped into juniors (semester 1 to 5 ) and seniors (semester 6 to 8 ). Juniors had completed a 20-hour addiction psychiatry module without clinical exposure. Seniors had finished both the 20-hour addiction psychiatry module and a onemonth addiction psychiatry rotation.

\section{Instrument}

The survey used the illness perception questionnaire revised version for addiction (IPQ-A), which has been validated in the Indonesian language. ${ }^{18}$ No other questionnaire assessing illness perception for addiction is available in the Indonesian language. This self-report questionnaire consists of three sections, but only the first two sections were utilized in this study since the last section, the attribution section, 
could not be applied to behavioral addiction. The participants should complete 38 questions focusing on perceptions of addiction. The time needed to complete this questionnaire is around $5 \mathrm{~min}$. It is subdivided into seven subscales: timeline chronic ("addiction is a chronic condition"), demoralization ("addiction is hopeless and helpless"), consequences ("addiction has severe consequences"), personal control ("patient can control addiction"), treatment control ("treatment can control addiction"), illness coherence ("I can understand addiction"), timeline cyclical ("addiction is a cyclical condition"), and emotional representation ("addiction is emotionally stressful"). All questions are answered on a 5-point Likert scale: strongly disagree (1), disagree (2), neither agree nor disagree (3), agree (4), and strongly agree (5). The higher score indicates better perception, accordingly to the subscales. The IPQ has good psychometric properties with reliability between 0.46 and $0.88 .{ }^{17}$

\section{Statistical analysis}

Data were collected and then analyzed statistically. Data were processed using SPSS, version 25 (IBM). Demographic factors are summarized into proportions for nominal variables and mean (standard deviation [SD]) for numeric variables. Demographic differences between groups were then analyzed using a chi-square test for nominal data and a MannWhitney $U$ test for continuous data. For the IPQ-A, the scores on the subscales of the perceptions section were computed according to the algorithm of the IPQ-R. Means (SD) for each subscale were calculated. The Mann-Whitney $U$ test was first used to determine the association of different years of exposure to psychiatric education and cases and the perception of internet addiction between the groups.

\section{RESULTS}

Fifty-two residents completed the survey. Of the total sample, 33 subjects were in the junior group, and 19 subjects were seniors (Table 1). More than 50\% of the samples in each group had internet availability in their residence and used a smartphone as their media of internet use. The cost of internet use per month between all groups were similar $(p=0.693)$. Communication was the reason for internet use in $37 \%$ of seniors, while $46 \%$ of juniors utilized the internet for entertainment.
Eighty-five percent of subjects felt that they did not have adequate knowledge on internet addiction. They thought that the current knowledge was not enough to make diagnosis and management decisions. Subjects had the lowest mean (SD) score of 1.882 (0.374) on the demoralization scale and the highest mean (SD) score of 4.139 (0.538) on the consequences scale. Comparison between groups showed that seniors had a higher understanding that addiction is emotionally stressful (emotional representation), about addiction itself (illness coherence), addiction is a chronic condition (timeline chronic), and addiction is a cyclical condition (timeline cyclical) compared with juniors. Juniors had significantly lower scores on the consequence scale, with mean (SD) scores of 4.1 (0.54) for juniors and 4.4 $(0.48)$ for seniors $(p=0.021)$.

\section{DISCUSSION}

Up to this day, this is the only published study in Indonesia about psychiatric residents that aimed to assess the perception of psychiatric residents of internet addiction, using the total sampling method. According to this study, most residents have continuous access to the internet and use it frequently. They perceive internet addiction as emotionally stressful, understandable, cyclical, but difficult to control. Similar to other kinds of addiction, internet addiction is certainly regarded as a chronic disorder with severe consequences. In this study, senior residents had higher scores on the consequence scale than intermediate residents. This finding might be due to seniors having more exposure to addiction patients compared with other residents. They could have gained more experience with the 'real' consequences of addiction for patients and families compared with only reading the theory of consequences from books or articles. As internet addiction gains popularity, some residents might have seen or helped their consultant psychiatrist manage this condition. Nevertheless, internet addiction is still a very controversial diagnosis, and research related to this topic has not yet been standardized. Residents, who ought to learn based on evidence, are expected to have correct knowledge and attitudes based on limited data.

Renner et $a^{10}$ describes an adequate knowledge base, appropriate attitudes, and a sense of professional responsibility as the "clinician's triad" required for 
Table 1. Characteristics and IPQ score of subjects

\begin{tabular}{|c|c|c|c|}
\hline Variables & Juniors, $\mathrm{n}(\%)(\mathrm{N}=33)$ & Seniors, $n(\%)(N=19)$ & $p$ \\
\hline Age (years), mean (SD) & $29.15(3.22)$ & $33.95(4.81)$ & $<0.001$ \\
\hline Male gender & $13(39)$ & $4(21)$ & 0.175 \\
\hline Availability of internet in residence & $32(97)$ & $16(84)$ & 0.096 \\
\hline Media of internet use & & & 0.400 \\
\hline Smartphone & $30(91)$ & $19(100)$ & \\
\hline Desktop/laptop & $2(6)$ & $0(0)$ & \\
\hline Tablet & $1(3)$ & $0(0)$ & \\
\hline Cost of internet use per month (IDR) & & & 0.693 \\
\hline$>400,000$ & $5(16)$ & $2(11)$ & \\
\hline $200,000-400,000$ & $6(16)$ & $5(26)$ & \\
\hline $100,000-200,000$ & $11(34)$ & $4(21)$ & \\
\hline $50,000-100,000$ & $11(34)$ & $8(42)$ & \\
\hline Routine online gaming & $21(64)$ & $7(37)$ & 0.062 \\
\hline Reasons of internet use & & & 0.210 \\
\hline Communication & $12(36)$ & $7(37)$ & \\
\hline Entertainment & $15(46)$ & $4(21)$ & \\
\hline Education & $3(9)$ & $4(21)$ & \\
\hline Information seeking & $3(9)$ & $4(21)$ & \\
\hline \multicolumn{4}{|l|}{ IPQ score, mean (SD) } \\
\hline Emotional representation & $3.7(0.82)$ & $4.0(0.71)$ & 0.080 \\
\hline Demoralization & $1.9(0.37)$ & $1.8(0.39)$ & 0.688 \\
\hline Illness coherence & $3.4(0.70)$ & $3.5(0.74)$ & 0.365 \\
\hline Consequences & $4.1(0.54)$ & $4.4(0.48)$ & 0.021 \\
\hline Timeline chronic & $3.4(0.66)$ & $3.5(0.73)$ & 0.441 \\
\hline Patient control & $4.1(0.59)$ & $4.0(0.62)$ & 0.240 \\
\hline Timeline cyclical & $3.1(0.69)$ & $3.2(0.55)$ & 0.460 \\
\hline Treatment control & $3.8(0.66)$ & $3.8(0.76)$ & 0.754 \\
\hline
\end{tabular}

$\mathrm{SD}=$ standard deviation; IPQ=illness perception questionnaire successful clinical care of patients with addictions. The curriculum for psychiatric residents in Indonesia includes the requirement of being able to diagnose and treat addiction cases. The addiction module consists of five academic credit systems throughout four years of residency. The theory of behavioral addiction is taught in the fifth semester. Clinical exposure involves a month of clinical work in a substance-use-disorderbased hospital. No specific requirement for behavioral addiction is regulated during this period. The results of this study showed that there were significant differences between senior and juniors residents in the perception that addiction could have serious consequences and understanding of the addiction process. This could mean that as residents gain more knowledge and experience, they would have a better perception of some aspects of addiction.
Although knowledge and perception are important parts of residents' preparation for caring for addiction patients, attitudes are also essential. Avery and Zerbo ${ }^{5}$ stated that residents' attitudes toward patients with addictions tend to worsen over time, despite increased knowledge and skills. It might be useful for the seminar to also explain the need for appropriate attitudes and a sense of professional responsibility in dealing with addiction cases. It is suggested that learning about negative countertransference in the form of a oneday educational conference or brief video- or skillbased didactics could be useful. Furthermore, the residents could be asked to perform a self-reflection on their experiences taking care of addiction patients. This might be done a minimum of two times during psychiatric residency to improve attitudes using revisitation of the topic. 
It has been reported that physicians who regularly use psychoactive substances showed more negative attitudes than others who do not use those substances. ${ }^{19}$ Those physicians have less legitimacy and awareness as they also used psychoactive substances and would not regard it as a serious problem. This could suggest that the use of the internet could also influence the perception of internet addiction among psychiatric residents. Despite the use of the internet at all locations and in all periods by most residents disturbing their daily activities, they might not perceive their usage as problematic. Lack of awareness of oneself could lead to insensitivity to the addiction symptoms and subsequently underdiagnosis.

This study has several limitations. As it is a singlecentered study, the generalization of the results is limited to other centers with similar resident characteristics. It might not reflect the perception of all psychiatric residents in other education centers. Second, the current knowledge of psychiatry residents about internet addiction was not measured. The residents might have adequate knowledge but still were not prepared to diagnose and treat internet addiction. These other factors were not explored in the study. Lastly, how perceptions and attributions of addiction change over time can be improved by education was not assessed. These problems should be addressed in future studies.

Senior psychiatric residents had better perception of the consequences of internet addiction compared to their juniors, who have received only basic knowledge about addiction without clinical exposure. Nevertheless, the perception could still be improved. Modification of the curriculum to include more topics related to internet addiction may be beneficial, so that psychiatric residents could become more prepared to screen, identify, manage, and refer cases of internet addiction to addiction specialists before the condition worsens. The residents could also have better empathy towards addiction patients so that the therapy could be given more effectively. The current psychiatric graduates could train primary health care providers so that services could be offered in primary health care as well.

\section{Conflicts of Interest}

The authors affirm no conflict of interest in this study.

\section{Acknowledgment}

None.
Funding Sources

The research was supported by grant from Universitas Indonesia, named Hibah Publikasi Terindeks Internasional untuk Tugas Akhir Mahasiswa UI 2018.

\section{REFERENCES}

1. Young KS, de Abreu CN. Internet addiction: a handbook and guide to evaluation and treatment. New Jersey: John Wiley \& Sons; 2011.

2. Montag C, Reuter M, editors. Internet addiction: neuroscientific approaches and therapeutical interventions. Switzerland: Springer International Publishing; 2015.

3. American Psychiatric Association. Diagnostic and statistical manual of mental disorders. 5th ed. Arlington: American Psychiatric Association; 2013.

4. World Health Organization. Gaming disorder [Internet]. Geneva: World Health Organization; 2018 [cited 2018 Oct 18]. Available from: http://www.who.int/features/qa/gaming-disorder/en/.

5. Avery J, Zerbo E. Improving psychiatry residents' attitudes toward individuals diagnosed with substance use disorders. Harv Rev Psychiatry. 2015;23(4):296-300.

6. Wakeman SE, Baggett MV, Pham-Kanter G, Campbell EG. Internal medicine residents' training in substance use disorders: a survey of the quality of instruction and residents' selfperceived preparedness to diagnose and treat addiction. Subst Abus. 2013;34(4):363-70.

7. Wakeman SE, Pham-Kanter G, Baggett MV, Campbell EG. Medicine resident preparedness to diagnose and treat substance use disorders: impact of an enhanced curriculum. Subst Abus. 2015;36(4):427-33.

8. Iannucci R, Sanders K, Greenfield SF. A 4-year curriculum on substance use disorders for psychiatry residents. Acad Psychiatry. 2009;33(1):60-6.

9. Barral C, Eiroa-Orosa FJ, Navarro-Marfisis MC, Roncero C, Casas $M$. Assessing knowledge and attitudes towards addictions in medical residents of a general hospital. Drugs Educ Prev Policy. 2015;22(6):457-62.

10. Renner JA Jr, Karam-Hage M, Levinson M, Craig T, Eld B. What do psychiatric residents think of addiction psychiatry as a career? Acad Psychiatry. 2009;33(2):139-42.

11. Springer CM, Tannert Niang KM, Matte TD, Miller N, Bassett MT, Frieden TR. Do medical students know enough about smoking to help their future patients? Assessment of New York City fourthyear medical students' knowledge of tobacco cessation and treatment for nicotine addiction. Acad Med. 2008;83(10):982-9.

12. Warren J, Cisler A, Weatherford J, Zakaria NS. Assessing the impact of addictions education on attitudes of students: a preliminary investigation. J Alcohol Drug Educ. 2013;57(3):18-26.

13. van Boekel LC, Brouwers EP, van Weeghel J, Garretsen HFL. Healthcare professionals' regard towards working with patients with substance use disorders: comparison of primary care, general psychiatry and specialist addiction services. Drug Alcohol Depend. 2014;134:92-8.

14. Schrimsher GW, Casey L, Nelson JS, Overstreet SE, Schaefer D, Williams SC. Substance use disorder education for medical students: reflections on our Betty Ford Institute training experience. Alcohol Treat Q. 2011;29(2):158-69.

15. Lindsay DL, Hagle $H$, Lincoln $P$, Williams J, Luongo PF. Exploring medical students' conceptions of substance use: a follow-up evaluation. Subst Abus. 2017;38(4):464-7.

16. Barron R, Frank E, Gitlow S. Evaluation of an experiential curriculum for addiction education among medical students. J Addict Med. 2012;6(2):131-6.

17. Susanti R. Internet addiction sufferers appear, watch for symptoms [Internet]. Jakarta: PT. Kompas Cyber Media; 2019 [cited 2019 Mar 4]. Available from: https://lifestyle.kompas. com/read/2019/01/24/190000720/penderita-kecanduan-internet- 
bermunculan-perhatikan-gejalanya-?page=all.

18. Ayu AP, Dijkstra B, Golbach M, De Jong C, Schellekens A. Good psychometric properties of the addiction version of the revised illness perception questionnaire for health care professionals.
PLoS One. 2016;11(11):e0164262.

19. Raistrick D, Russell D, Tober $G$, Tindale A. A survey of substance use by health care professionals and their attitudes to substance misuse patients (NHS staff survey). J Subst Use 2008;13(1):57-69. 